\title{
TRANSFORMAÇÕES BIOQUÍMICAS DE ABACAXI MINIMAMENTE PROCESSADO ARMAZENADO SOB ATMOSFERA MODIFICADA ${ }^{1}$
}

\author{
MÔNICA ELISABETH TORRES PRADO ${ }^{2}$, ADIMILSON BOSCO CHITARRA ${ }^{3}$, DEBORAH SANTESSO BONNAS ${ }^{4}$, \\ ANA CARLA MARQUES PINHEIRO
}

\begin{abstract}
RESUMO - Realizou-se estudo sobre a influência da atmosfera modificada com diferentes concentrações de gases durante o armazenamento de abacaxi cv. Smooth cayennne minimamente processado, por oito dias, à temperatura de $5^{\circ} \mathrm{C}$ e $85 \%$ de UR. Foram realizadas análises de açúcares neutros, celulose, hemicelulose e poliuronídeos totais na parede celular. $\mathrm{O}$ abacaxi minimamente processado foi acondicionado sob duas Atmosferas Modificadas Ativas, uma com 5\% de $\mathrm{O}_{2}$ e $5 \%$ de $\mathrm{CO}_{2}$ (AM1), outra com 2\% de $\mathrm{O}_{2}$ e $10 \%$ de $\mathrm{CO}_{2}$ (AM2), e uma Atmosfera Modificada Passiva (Controle) durante 8 dias de armazenamento. $\mathrm{O}$ uso de atmosferas modificadas ativas permitiu que o abacaxi minimamente processado sofresse menor degradação da parede celular com menor solubilização das hemiceluloses. Abacaxis minimamente processados e armazenados sob atmosfera modificada obtiveram uma vida de prateleira média de 6 dias, a $5^{\circ} \mathrm{C}$.
\end{abstract}

Termos de indexação: Processamento mínimo, cromatografia gasosa, cromatografia gélica, açúcares neutros, Ananas comosus L. Merr.

\section{BIOCHEMICAL MODIFICATIONS OF PINEAPPLE MINIMALLY PROCESSED UNDER MODIFIED ATMOSPHERE}

\begin{abstract}
Pineapples minimally processed were, stored eight days $\left(5^{\circ} \mathrm{C}\right.$ and $\left.85 \% \mathrm{RH}\right)$ under passive and active atmosphere (MA). Neutral sugars, cellulose, hemicellulose, and total polyuronide analysis in cell wall were done. Two different active MA were tested: $5 \%$ of $\mathrm{O}_{2}+5 \%$ of $\mathrm{CO} 2(\mathrm{MA} 1)$ and $2 \%$ of $\mathrm{O}_{2}+10 \%$ of $\mathrm{CO}_{2}$ (MA2) and one passive MA (Control); during eight days of storage. Pineapples minimally processed stored under active modified atmosphere showed degradation of cell wall and less solubilization of hemicelluloses, besides being more effective in control of ethanol production and formation of off flavours. Pineapples minimally processed stored under modified atmosphere, showed life average of 6 days under refrigeration at $5^{\circ} \mathrm{C}$.
\end{abstract}

Index terms: minimally processed, gaseous chromatography, gel filtration, neutral sugars, Ananas comosus L. Merr.

\section{INTRODUÇÃO}

Uma grande mudança nos padrões de consumo de alimentos vem ocorrendo nas últimas décadas. Tem-se observado que os consumidores estão mais preocupados com a saúde quanto à escolha de seus alimentos. Frutas e hortaliças frescas têm aumentado em popularidade em detrimento dos produtos industrializados. Ao mesmo tempo, desejam-se produtos de alta qualidade, de fácil preparo e consumo. Como resultado, a demanda por frutas e hortaliças "minimamente processadas" tem crescido rapidamente.

Frutos minimamente processados são produtos que reúnem os atributos de conveniência e qualidade do produto fresco. Suas formas variam largamente, dependendo da natureza do produto não processado e de como normalmente é consumido (Durigan, 2000).

O processamento mínimo de frutos provoca alterações na sua fisiologia e pode comprometer a sua vida de prateleira, caso tais alterações não sejam controladas através de cuidados adequados. Acredita-se que estas alterações estejam intimamente associadas a mudanças estruturais da parede celular e suas enzimas. A parede celular é uma intrincada associação entre carboidratos, proteínas e compostos fenólicos, responsáveis pela salvaguarda da estrutura celular. $\mathrm{O}$ processamento mínimo inadequado pode desorganizar esta estabilidade celular através da produção de etileno, ativação enzimática e contato entre enzimas e substrato (Moretti, 2001).

Visto que a popularidade dos produtos minimamente processados tem sido incrementada nos últimos anos, devido aos aspectos de conveniência e satisfação do consumidor, e face aos incipientes estudos referentes aos efeitos deste processamento sobre a fisiologia do produto, principalmente aqueles relacionados às modificações dos componentes da parede celular, o presente trabalho teve como objetivo avaliar a influência da atmosfera modificada em diferentes concentrações de oxigênio e dióxido de carbono sobre a qualidade do abacaxi Smooth cayenne minimamente processado, através da determinação dos teores de açúcares neutros, celulose, hemicelulose e poliuronídeos totais no produto minimamente processado.

\section{MATERIAL E MÉTODOS}

Material- Foram utilizados frutos do abacaxizeiro (Ananas comosus L. Merr) cv. Smooth cayenne, oriundos de Monte Alegre-MG. Os frutos foram colhidos no estádio 2 de maturação (Py et al., 1984) e armazenados por $1 \mathrm{dia}, \mathrm{a} 5^{\circ} \mathrm{C}$, antes do início do trabalho.

Processamento do fruto- Os abacaxis, após serem lavados com água e detergente neutro e sanificados em cloro ativo (200 ppm) por 15 minutos, a $5^{\circ} \mathrm{C}$, foram descascados manualmente, com facas de aço inox devidamente afiadas e sanificadas, fazendo-se uso de luvas, máscaras e toucas descartáveis na sua manipulação. Em seguida, foram cortados em palitos, no sentido longitudinal do fruto, com $10 \mathrm{~mm}$ de lado e $40 \mathrm{~mm}$ de comprimento, utilizando-se de um multiprocessador MASTER AT. Estes palitos foram sanificados, por imersão em solução de cloro ativo a $100 \mathrm{ppm}, \mathrm{a} 5^{\circ} \mathrm{C}$, durante 3 minutos, conforme literatura consultada (Rocha, Brochado e Morais, 1996). Realizou-se drenagem dos palitos por 10 minutos, utilizando-se de peneiras de plástico, para a retirada do excesso de líquido acumulado nas etapas anteriores. Feito o processamento, os frutos foram acondicionados em embalagem $(13,5 \mathrm{~cm}$ de comprimento $\mathrm{x}$ $10,0 \mathrm{~cm}$ de largura $\mathrm{x} 4,0 \mathrm{~cm}$ de altura) de polietileno terefitalato barreira média e selados com filme flexível de polietileno + polipropileno alta barreira (60 micras) da FRUTPACK, em seladora a vácuo, fazendo-se uso de injeção de gases da modificação da atmosfera (AM). Foram utilizados três tratamentos: Atmosfera Modificada Passiva (Controle), Atmosfera Modicada Ativa, com 5\% de $\mathrm{O}_{2}$ e $5 \%$ de $\mathrm{CO}_{2}$ (AM1), e Atmosfera Modificada Ativa, com 2\% $\mathrm{O}_{2}$ e $10 \%$ de $\mathrm{CO}_{2}$ (AM2). As embalagens com cerca de $150 \mathrm{~g}$ do produto foram armazenadas sob refrigeração $\left(5^{\circ} \mathrm{C}\right)$, em câmara fria com $85 \%$ de UR. Foram realizadas análises de açúcares neutros, celulose, hemicelulose e poliuronídeos na parede celular, em intervalos de 2 dias, até o $8^{\circ}$ dia de armazenamento.

\footnotetext{
${ }^{1}$ (Trabalho 062/2004). Recebido: 27/05/2004. Aceito para publicação: 17/09/2004.

${ }^{2}$ Pesquisadora Doutora do Departamento de Ciência dos Alimentos-UFLA- bolsista CNPq-monica@ufla.br

${ }^{3}$ Professor Titular do Departamento de Ciência dos Alimentos-UFLA- chitarra@ufla.br.

${ }^{4}$ Doutora em Ciência dos Alimentos- dbonnas@uol.com.br.

${ }^{5}$ Aluna de Doutorado do Departamento de Ciência dos Alimentos-UFLA-ana.carla@ posgrad.ufla.br.
} 
Extração da Parede Celular- A parede celular foi extraída do tecido mesocárpico como descrito por Mitcham e McDonald (1992), com modificações. O mesocarpo $(100 \mathrm{~g})$ foi triturado em homogeneizador de tecidos (Polytron- Tekmar Company) com etanol 80\% (100 mL). O resíduo foi lavado com tampão fosfato $50 \mathrm{mM}, \mathrm{pH} 6,8(200 \mathrm{~mL})$ e filtrado sob vácuo. Adicionaram-se $70 \mathrm{~mL}$ de fenol: ácido acético: água (2:1:1 v/ v) e manteve-se em repouso por 20 minutos. Lavou-se novamente o resíduo com tampão fosfato $50 \mathrm{mM}, \mathrm{pH} 6,8(200 \mathrm{~mL})$. A parede celular foi sucessivamente lavada com clorofórmio: metanol $(1: 1 \mathrm{v} / \mathrm{v}) 70 \mathrm{~mL}$ e acetona ( 3 porções de $70 \mathrm{~mL}$ ), seguida de secagem sob vácuo, à temperatura ambiente.

O teor de celulose foi determinado em $2 \mathrm{mg}$ de parede celular que foram hidrolisados em $3 \mathrm{~mL}$ de $\mathrm{H}_{2} \mathrm{SO}_{4}$ a $72 \%$, por $12 \mathrm{~h}$. A concentração de celulose foi determinada pelo método da Antrona, segundo Dische (1962). Os resultados foram expressos em porcentagem de celulose na parede celular.

O conteúdo de hemicelulose total foi determinado em $2 \mathrm{mg}$ de parede celular os quais foram solubilizados em $1 \mathrm{~mL}$ de ácido trifluoracético a $2 \mathrm{~N}$, a $120^{\circ} \mathrm{C}$, por $1 \mathrm{~h}$, diluído em $50 \mathrm{~mL}$ de água destilada e filtrado em papel de filtro. Os açúcares neutros no filtrado também foram determinados através do método da antrona (Dische, 1962) e os resultados expressos em porcentagem de hemicelulose na parede celular.

O teor de poliuronídeos totais foi determinado em $2 \mathrm{mg} \mathrm{de}$

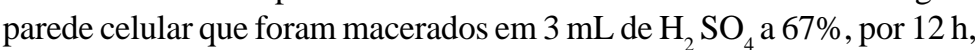
e o teor de ácidos urônicos doseado pelo método do carbazol (Bitter e Muir, 1962) com os resultados expressos em porcentagem de ácido galacturônico .

Fracionamento da parede celular- $\mathrm{O}$ fracionamento da parede celular foi realizado de acordo com Ranwala et al. (1992). O material da parede celular foi incubado em EDTA a 0,5\%, em tampão fosfato $50 \mathrm{mM}$, pH 6,8 $(200 \mathrm{~mL})$, por 4 horas, a $100^{\circ} \mathrm{C}$. O extrato, após filtragem, foi designado como fração solúvel em EDTA $0,5 \%$ (fração péctica). O resíduo foi lavado extensivamente com água destilada (2 litros) e incubado com $\mathrm{KOH}$ a $4 \mathrm{M}$, por 24 horas, a $30^{\circ} \mathrm{C}$. O extrato foi filtrado e, subseqüentemente, neutralizado com ácido acético. $\mathrm{O}$ filtrado neutralizado foi submetido à diálise com agitação ininterrupta, por 72 horas, com 12 trocas de água destilada, seguida de liofilização, por 72 horas, obtendo-se, assim, a fração da parede celular solúvel em $\mathrm{KOH}$ a 4M (fração hemicelulósica).

Cromatografia Gélica da fração da parede celular solúvel em EDTA 0,5\% (fração poliuronídica) e KOH 4M (hemicelulose) Quantidades equivalentes da fração péctica (cerca de 1,5 mg de uronídeos) foram solubilizadas em tampão e aplicadas na coluna, após filtragem em papel de filtro. A corrida gélica dos poliuronídeos foi realizada em coluna pré-empacotada Sephacryl S-200, 16/60, "high resolution", Pharmacia Biotech, eluída com tampão fosfato a $50 \mathrm{mM}, \mathrm{pH}$ 6,8. A calibração da coluna para a hemicelulose foi feita com "blue dextran" (2000 kDa), dextranas de $40 \mathrm{kDa}$ e $70 \mathrm{kDa}$ e glicose, e para os poliuronídeos, utilizaram-se pectina de alto peso molecular e ácido galacturônico. O fluxo do sistema foi ajustado em $20 \mathrm{~mL}$ por hora. Após cada etapa de fracionamento, fez-se a lavagem do sistema, permitindo-se a passagem de tampão correspondente a 2 vezes o seu volume total. Frações de $2 \mathrm{~mL}$ foram coletadas e os teores de ácidos urônicos e hemicelulose analisados, utilizando-se de 1,0 $\mathrm{mL}$ do efluente (Bitter e Muir, 1962).

Cromatografia gasosa : Açúcares Neutros - As amostras derivatizadas, de acordo com o método preconizado por Albersheim et al. (1967), foram diluídas com $200 \mu \mathrm{L}$ de acetona e injetados $(2 \mu \mathrm{L}) \mathrm{em}$ cromatógrafo a gás modelo VARIAN 3800 com coluna capilar OV-DB $225,0,25 \mathrm{~mm}$ de diâmetro interno e $25 \mathrm{~m}$ de comprimento, acoplado a um integrador.

Os gases utilizados foram o hidrogênio como gás de queima, o ar sintético como mantedor da chama e o "make up", uma mistura de hidrogênio e nitrogênio $\left(30 \mathrm{~mL} \cdot \mathrm{min}^{-1}\right)$. Utilizou-se sensibilidade $10^{-11} \mathrm{e}$ atenuação 10. A pressão da coluna foi de $21 \mathrm{psi}$, o fluxo da coluna 1,0 $\mathrm{mL} \cdot \mathrm{min}^{-1}$ e a do gás de arraste $30 \mathrm{~mL} \cdot \mathrm{min}^{-1}$. Foram utilizadas as seguintes temperaturas: coluna $210^{\circ} \mathrm{C}$, injetor $250^{\circ} \mathrm{C}$ e detetor $300^{\circ} \mathrm{C}$. Utilizou-se como padrão uma mistura dos açúcares ramnose, fucose, arabinose, xilose, manose, galactose, glicose e inositol (padrão interno), todos na concentração de $400 \mu \mathrm{L} . \mathrm{mL}^{-1}$ (De Veten e Huber, 1990; Hwang et al.,1990).

Delineamento Experimental- O experimento foi conduzido em delineamento inteiramente casualizado (DIC), em fatorial $3 \times 5$ ( 3 atmosferas e 5 tempos de amostragem), com 3 repetições. A parcela experimental foi constituída de uma bandeja contendo $150 \mathrm{~g}$ de fruto. Foi realizada a análise de variância e teste de médias (Tukey).

\section{RESULTADOS E DISCUSSÃO}

Celulose- A evolução do teor de celulose foi semelhante nos palitos de abacaxi dos diversos tratamentos com atmosfera modificada ativa, com tendência de aumento com o tempo de armazenamento (Figura 1). Observa-se, pela Tabela 1 , diferença significativa entre os tratamentos com atmosfera modificada ativa $\left(5 \% \mathrm{O}_{2}\right.$ e $5 \% \mathrm{CO}_{2}-\mathrm{AM} 1 ; 2 \% \mathrm{O}_{2}$ e $10 \%$ $\mathrm{CO}_{2}-\mathrm{AM} 2$ ) e o controle. Os tratamentos com $5 \% \mathrm{O}_{2}+5 \% \mathrm{CO}_{2}$ e $2 \% \mathrm{O}_{2}$ $+10 \% \mathrm{CO}_{2}$ apresentaram valores médios maiores de celulose na parede celular, não diferindo significativamente entre si no teste de Tukey, ao nível de 5\% de probabilidade (Tabela 1). O aumento nos teores de celulose, principalmente no produto armazenado em atmosfera modificada ativa, pode ser considerado como mais um fator na manutenção da firmeza, $o$ que leva a crer que os tratamentos com atmosfera modificada ativa foram mais eficientes.

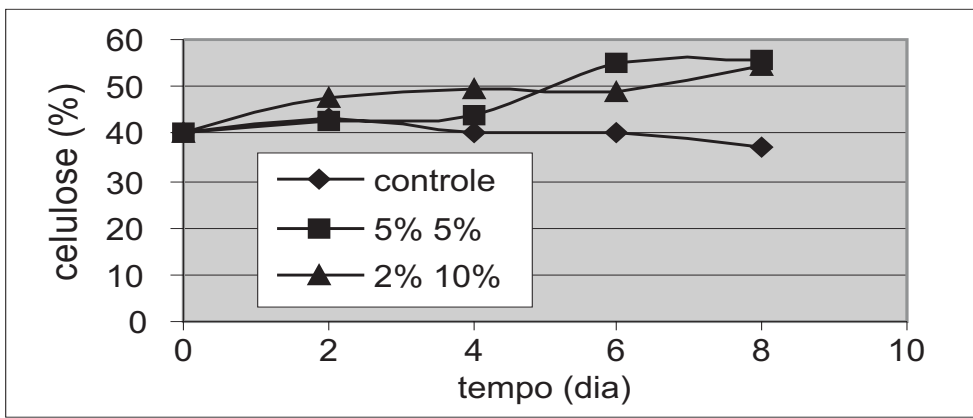

FIGURA 1 - Teores médios de celulose (\%) da parede celular de frutos do abacaxizeiro cv. Smooth cayenne minimamente processado, armazenado a $5^{\circ} \mathrm{C}$ e $85 \%$ UR, durante 8 dias.

TABELA 1 - Teores médios de celulose, hemicelulose e poliuronídeos (\%) de abacaxi Smooth cayenne minimamente processado (controle-AMP, $5 \%$ O e $5 \% \mathrm{CO}_{2}-\mathrm{AM} 1,2 \% \mathrm{O}_{2}$ e $10 \%$ $\mathrm{CO}_{2}-\mathrm{AM} 2$ ), armazenado a $5^{\circ} \mathrm{Ce} 85 \% \mathrm{UR}$, durante 8 dias.

\begin{tabular}{cccc}
\hline \multicolumn{3}{c}{ Variáveis } \\
\hline Tratamentos & Celulose & Hemicelulose & Poliuronídeos \\
Controle & $38,05 \mathrm{a}$ & $18,86 \mathrm{~b}$ & $16,72 \mathrm{a}$ \\
AM1 & $48,75 \mathrm{~b}$ & $15,20 \mathrm{a}$ & $16,16 \mathrm{a}$ \\
AM2 & $47,68 \mathrm{~b}$ & $19,08 \mathrm{~b}$ & $18,33 \mathrm{a}$ \\
\hline
\end{tabular}

Médias seguidas da mesma letra na mesma linha não diferem estatisticamente entre si, pelo teste de Tukey, a nível de 5\% de probabilidade

Hemicelulose- A hemicelulose é um polissacarídeo heterogêneo constituído por açúcares neutros que interagem com a celulose e as substâncias pécticas. Pela Figura 2, observou-se, de modo geral, uma redução no teor de hemicelulose com o tempo de armazenamento, exceto para o tratamento com $5 \%$ de $\mathrm{O}_{2}$ e $5 \%$ de $\mathrm{CO}_{2}$, onde o teor de hemicelulose permaneceu inalterado, concordando com resultados obtidos por Filgueiras (1996) e Vilas Boas (1998). O tratamento com atmosferas modificadas também revelou diferenças estatisticamente significativas entre o tratamento AM1 ( $5 \%$ de $\mathrm{O}_{2}$ e $5 \%$ de $\mathrm{CO}_{2}$ ) e os demais, mostrando que este tratamento promoveu menor redução na hemicelulose, no período analisado (Tabela 1).

Poliuronídeos- Quanto aos teores de poliuronídeos, os tratamentos (atmosferas modificadas) não diferiram entre si $(\mathrm{p}<0,05)$ conforme mostra a Tabela 1. Os teores de pectina total aumentaram com o tempo de armazenamento em todos os tratamentos analisados, não 


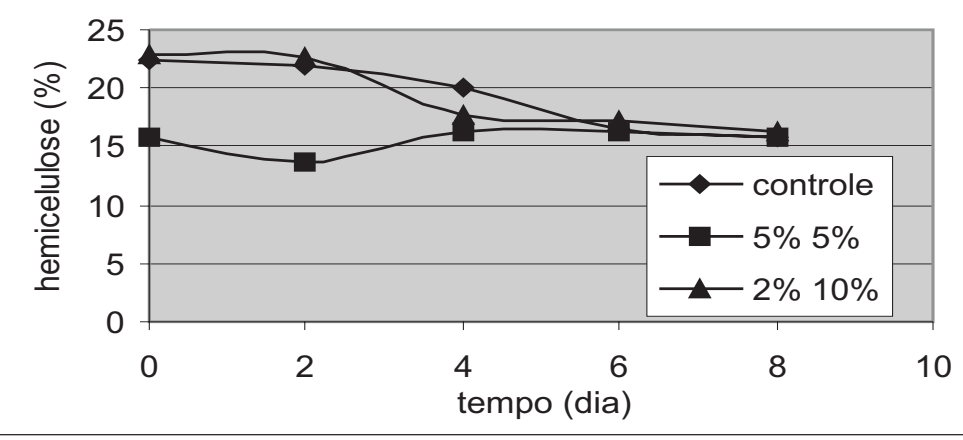

FIGURA 2 - Valores médios de hemicelulose total(\%) da parede celular de frutos do abacaxizeiro cv. Smooth cayenne minimamente processado, armazenado a $5^{\circ} \mathrm{C}$ e $85 \%$ UR, durante 8 dias.

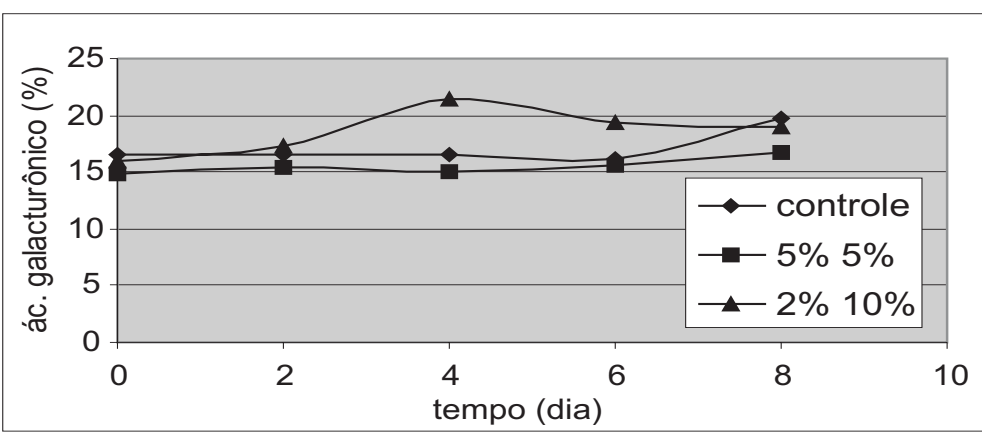

FIGURA 3 - Valores médios de pectina total (\% ácido galacturônico) da parede celular de frutos do abacaxizeiro cv. Smooth cayenne minimamente processado, armazenado a $5^{\circ} \mathrm{C}$ e $85 \%$ UR, durante 8 dias

apresentando diferença estatística também para a variável tempo de armazenamento, como pode ser visualizado pela Figura 3. Pequenas alterações podem ser observadas para o tratamento AM2, porém estas não foram significativas ao nível de $5 \%$ de probabilidade, pelo teste de Tukey. As modificações que ocorrem com os polissacarídeos da parede celular, durante o armazenamento de frutos, são os principais determinantes de suas alterações texturais.

Açúcares Neutros- Os açúcares neutros predominantes no início do armazenamento do abacaxi Smooth cayenne minimamente processado foram a arabinose, xilose, galactose e glicose . Estes resultados concordam com os observados por outros autores, tais como Mitchan e McDonald (1992), Brinson (1988) e Lima (1999).

Durante o armazenamento, todos os açúcares neutros diminuíram até o sexto dia de armazenamento para todos os tratamentos analisados e, a partir daí, esses açúcares sofreram acentuado aumento nos seus teores ( $8^{\circ}$ dia), como pode ser visualizado pela Tabela 2. Evangelista (1999) também observou diminuição nos teores de ramnose, fucose, arabinose, galactose e glicose, durante o armazenamento de mangas.

Com o armazenamento dos frutos, houve perda líquida dos principais componentes dos polissacarídeos pécticos (galactose, arabinose e ramnose), enquanto a glicose (componente da fração hemicelulósica) sofreu aumento, como detectado por Mitchan e McDonald (1992).

As menores concentrações de arabinose, galactose e ramnose (no $6^{\circ}$ dia de armazenamento) na parede celular são indicativos de um elevado grau de despolimerização. A acentuada redução nos teores de ramnose da parede celular, juntamente com os de arabinose e galactose, possivelmente indicam que as cadeias principais dos polímeros pécticos se tornaram mais lineares, pois os resíduos de ramnose introduzem pontos de hidrólise na sua conformação.

Estudos relativos a maçãs sugerem que a perda líquida de resíduos de açúcares neutros da parede celular (PC) durante o armazenamento, ou a maturação, pode ser atribuída à perda de cadeias laterais de pectinas (Fischer et al., 1994).

Knee (1973) verificou que, das alterações que ocorrem na PC, uma delas é a diminuição de galactose e da arabinose na fração insolúvel em água da PC. Knee et al. (1975) explicam que a perda de resíduos da galactose é proveniente da hidrólise de galactanas da PC primária pela ação da $\beta$-galactosidase.

Gross e Sams (1984) também encontraram altos níveis de arabinose, xilose e galactose na PC de maçãs, resultado condizente aos encontrados para o abacaxi minimamente processado do presente trabalho.

Fração solúvel em EDTA: substâncias pécticas- O perfil cromatográfico gélico obtido na coluna Sephacryl S-200, com soluções de ácido poligacturônico de alto peso molecular e D-galacturônico, está representado na Figura 4

Não se detectou nenhum pico de poliuronídeos na coluna S200 em todos os tratamentos, com possíveis indicações de ineficiência do EDTA na extração desses polímeros.

Fração solúvel em KOH: hemicelulose- As hemiceluloses representam complexa rede da parede celular polissacarídea, usualmente agrupada sobre a base da sua solubilidade em álcali. A composição e outras propriedades destes polímeros dependem do método pelo qual eles são extraídos.

A extensão do peso molecular das frações solúveis em $\mathrm{KOH}$ foi estimada calibrando-se a coluna pré-empacotada Sephacryl S-200, 16/ 60, "high resolution" com Azul Dextrana 2000 (volume vazio), dextranas de peso molecular $70 \mathrm{Kda}, 40 \mathrm{Kda}$ e glicose (Figura 5).

O Controle (Atmosfera Modificada Passiva) foi, dentre os três tratamentos, o que apresentou maior solubilização da hemicelulose e aumento da glicose (baixo peso molecular) com o decorrer do tempo. Pela Figura 6, nota-se o pico evidenciado da glicose no $8^{\circ}$ dia de armazenamento do produto, e, se comparado ao pico do tratamento AM1 (Figura 7), apresenta valor bem mais alto de absorbância, indicando maior solubilização da hemicelulose no tratamento-Controle.

Deste modo, pode-se indicar o tratamento AM2 (Figura 8) como o mais adequado nesse caso, ou seja, manutenção da integridade da

TABELA 2 - Valores médios obtidos para o teor de açúcares neutros não celulósicos na parede celular do abacaxi Smooth cayenne minimamente processado, armazenado a $5^{\circ} \mathrm{C}$ e $85 \%$ UR

\begin{tabular}{c|c|c|c|c|c|c|c|c}
\hline \multicolumn{2}{c}{ Açúcares ( g/ g PC) } \\
\hline tempo & trat & ramnose & fucose & arabinose & xilose & manose & galactose & glicose \\
2 & AMP & 24,10 & 23,15 & 450,04 & 1100,12 & 35,01 & 280,22 & 290,23 \\
& AM1 & 23,89 & 23,68 & 436,43 & 1020,40 & 34,43 & 277,73 & 288,59 \\
& AM2 & 19,22 & 26,22 & 544,07 & 906,56 & 25,88 & 308,37 & 197,41 \\
4 & AMP & 17,84 & 24,77 & 483,73 & 882,71 & 43,14 & 369,23 & 413,13 \\
& AM1 & 11,84 & 17,47 & 386,57 & 732,25 & 52,75 & 293,67 & 491,55 \\
6 & AM2 & 13,22 & 17,73 & 354,04 & 749,34 & 54,10 & 273,81 & 434,10 \\
& AMP & 0,0454 & 0,057 & 1,2822 & 2,8615 & 0,0611 & 0,7382 & 0,3321 \\
& AM1 & 0,0348 & 0,0853 & 1,4656 & 2,4606 & 0,0837 & 0,9946 & 0,4122 \\
& AM2 & 0,0388 & 0,0410 & 0,9338 & 2,4280 & 0,0647 & 0,5914 & 0,5099 \\
& AMP & 10,44 & 29,04 & 608,59 & 1083,55 & 28,26 & 423,24 & 84,45 \\
& AM1 & 23,40 & 26,67 & 483,63 & 878,15 & 37,71 & 343,50 & 176,63 \\
\hline
\end{tabular}


rede de hemicelulose do abacaxi minimamente processado, armazenado durante oito dias, a $5^{\circ} \mathrm{C}$.

A relação entre a diminuição de polímeros de alto peso molecular e o aumento de polímeros de baixo peso molecular não é conhecida.

É possível que as mudanças observadas, particularmente a diminuição dos polímeros de alto peso molecular, reflitam uma diminuição nos resíduos de xilose, galactose e arabinose na parede celular, conforme constatado pelos teores de açúcares neutros

Huber (1983), trabalhando com tomates, verificou que

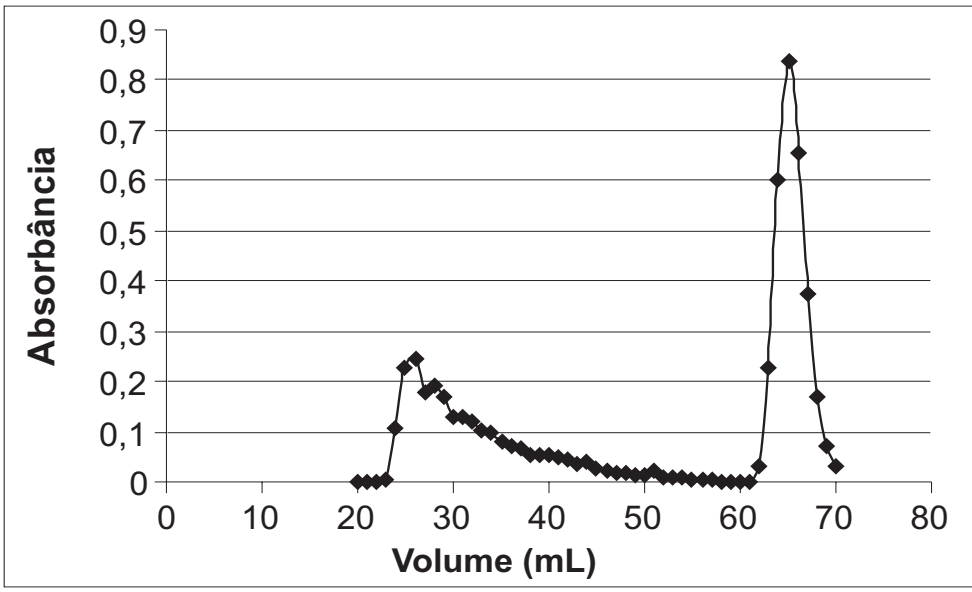

FIGURA 4 - Perfil cromatográfico de poliuronídeos (pectina e ácido gacturônico) em coluna Sephacryl S-200

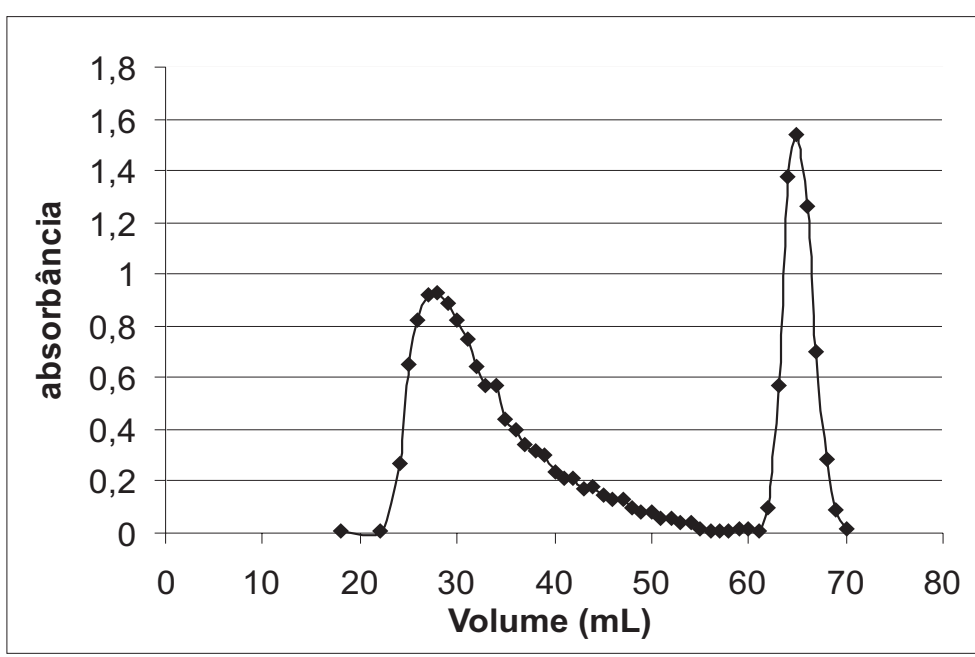

FIGURA 5 - Perfil cromatográfico obtido a partir de Coluna Sephacryl S200, utilizando-se de dextrana

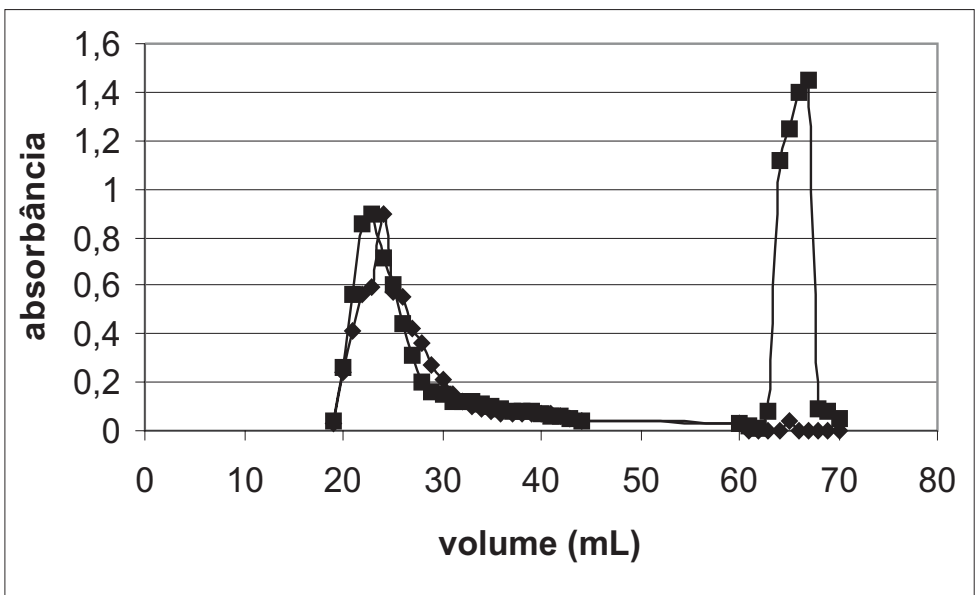

FIGURA 6 - Representação gráfica do perfil gel-cromatográfico de hemicelulose extraída com KOH de abacaxi cv. Smooth cayenne minimamente processado, armazenado em Atmosfera modificada passiva (Controle), no tempo 0 e 8 , em Coluna Sephacryl S-200.

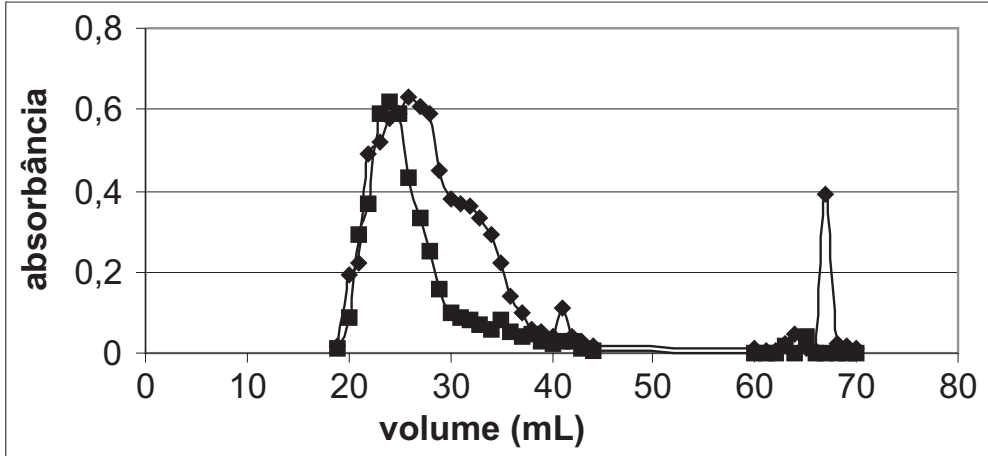

FIGURA 7 - Representação gráfica do perfil gel-cromatográfico de hemicelulose extraída com KOH de abacaxi cv. Smooth cayenne minimamente processado, armazenado em AM1 ( $5 \%$ de $\mathrm{O}_{2}$ e $5 \%$ de $\mathrm{CO}_{2}$ ), no tempo 0 e 8 , em Coluna Sephacryl S-200.

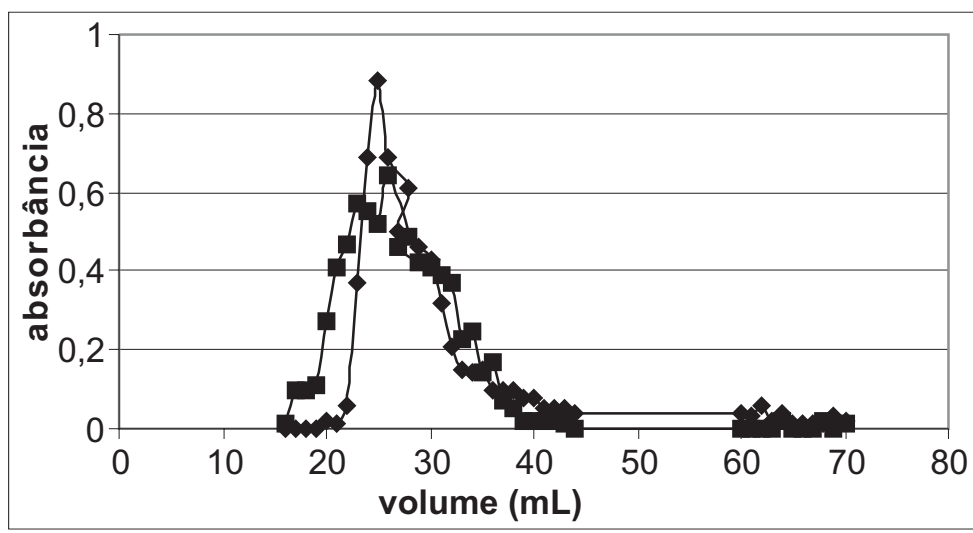

FIGURA 8 - Representação gráfica do perfil gel-cromatográfico de hemicelulose extraída com KOH de abacaxi cv. Smooth cayenne minimamente processado, armazenado em AM2 ( $2 \%$ de $\mathrm{O}_{2}$ e $10 \%$ de $\mathrm{CO}_{2}$ ), no tempo 0 e 8 , em Coluna Sephacryl S-200.

hemiceluloses de baixo peso molecular aumentaram durante o amadurecimento dos mesmos. Segundo esse autor, o aumento nos polímeros de baixo peso molecular deve possivelmente ser resultado da modificação de polímeros existentes ou talvez da diminuição do metabolismo acompanhado pela adição de polímeros já modificados na parede celular recentemente sintetizada. Os resultados indicam maior despolimerização do Controle em relação à AM1 e AM2, quando comparados no tempo inicial e final.

No produto armazenado a 5\%O2 e $5 \% \mathrm{CO}_{2}$ (AM1), verificou-se que, com o aumento do tempo de armazenamento, houve maior alargamento do pico referente ao volume de vazios, indicando maior degradação da hemicelulose, conforme se pode observar na Figura 7 (0 e 8 dias de armazenamento) . O aparecimento do pico da glicose deu-se somente no oitavo dia de armazenamento, evidenciando a diminuição nos polímeros de alto peso molecular e aumento nos polímeros de baixo peso molecular.

Em relação ao tratamento $\mathrm{AM} 2\left(2 \% \mathrm{O}_{2}\right.$ e $\left.10 \% \mathrm{CO}_{2}\right)$, o perfil cromatográfico evidencia também, perda dos polímeros de alto peso molecular com o tempo. No início do armazenamento (tempo 0 - Figura 8), o produto apresentou maiores valores de absorbância (maior teor de hemicelulose) quando comparado com o produto armazenado até o $8^{\circ}$ dia, que, além de apresentar menor absorbância, mostra o alargamento do pico conforme se pode visualizar na mesma Figura 8. Entretanto não houve aparecimento de polímeros de baixo peso molecular (glicose) em ambos os tempos analisados dentro deste tratamento.

\section{CONCLUSÕES}

1) O uso de atmosferas modificadas ativas permite concluir que o abacaxi cv. Smooth cayenne minimamente processado sofre menor 
degradação da parede celular com menor solubilização das hemiceluloses, conforme constatado através da cromatografia gélica. O Controle diferencia-se bastante destas atmosferas, mostrando a formação de considerável pico de glicose no oitavo dia de armazenamento, o que indica a total degradação do produto no final do período de armazenamento.

2) Os açúcares neutros predominantes no início do armazenamento do abacaxi minimamente processado são: arabinose, xilose, galactose e glicose, que decrescem até o sexto dia de armazenamento.

3) Abacaxis minimamente processados, armazenados sob atmosfera modificada, obtiveram vida de prateleira média de 6 dias sob refrigeração a $5^{\circ} \mathrm{C}$, pelas análises de celulose, hemicelulose, poliuronídeos totais e pelas cromatografias gasosa e gélica realizadas no produto.

\section{REFERÊNCIAS}

ALBERSHEIM, P.; NEVINS, D.; ENGLISH,P.; KARR, A . A method for the analysis off sugars in planr cell wall polyssacaharides by gasliquid chromatography. Carbohydrate Research, Amsterdan, n.5, p.340-345, 1967.

BITTER, T; MUIR, H.M. A modified uronic acid carbazole reaction. Analytical Biochemistry, New York, v.34, p.330-334, 1962.

BRINSON, K.; DEY, P.M.; JONH, M.A . et al. Post-harvest changes in Mangifera indica mesocarp cell wall and cytoplasmic polissaccharides. Phytochemistry, Oxford, v.27, n.3, p. 719-723, 1988.

DE VETTEN, N.C.; HUBER, D.J. Cell wall changes during the expansion and senescence of carnation (Dianthus caryopyllus) petals. Physiologia Plantarum, v.78, p.447-454, 1990.

DISCHE, Z. General color reactions. In: Whistler, R. L.; Wolfran, M. L. (Ed.) Carboydrates chemistry. New York: Academic Press, 1962. v.1, p.477-512.

DURIGAN, J.F. O processamento mínimo de frutas. In: CONGRESSO BRASILEIRO DE FRUTICULTURA, 16., 2000, Fortaleza-CE. Palestras......Fortaleza: Embrapa Agroindústria Tropical/ SBF, 2000. p.244-253.

EVANGELISTA, R.M. Qualidade de mangas “ Tommy Atkins" armazenadas sob refrigeração e tratadas com cloreto de cálcio pré-colheita. 1999.129f. Tese (Doutorado) - Universidade Federal de Lavras, Lavras, 1999.

FILGUEIRAS, H.A..C. Bioquímica do amadurecimento de tomates híbridos heterozigotos no loco “ alcobaça”. 1996. 118f. Tese (Doutorado) - Universidade Federal de Lavras, Lavras, 1996.

FISHER, M.; ARRIGONI, E.; AMADO, R. Changes in the pectic substances of apples during development and postharvest ripening. Cap.2: Analysis of the pectic fractions. Carbohydrate Polymers, Kidlington, v.25, p.167-175, 1994.

GROSS, K.C.; SAMS, C.E. Changes in cell wall neutral sugar composition during fruit ripening: a species survey. Phytochemistry, Oxford, v.23, n.11, p.2457-2461, Nov, 1984.

HUBER, D.J. Polyuronide degration and hemicelulose modifications in ripenig tomato fruit. Journal of American Society for Horticultural Science, Alexandria, VA, v.108, n.3, p.405-409, May 1983.

HWANG, Y-S; HUBER, D.J.; ALBRIGO, L.G. Comparison of cell wall components in normal and disordered juice vesicles of grapefruit. Journal of the American Society for Horticultural Science, Alexandria, v.115, n.2, p.281-287, 1990.

KNEE, M. Polissaccharide changes in cell wall of ripening apples. Phytochemistry, Oxford, v.12, p.1543-1549, July 1973.

KNEE, M.; FIELDING, A.; ARCHER, S. A. et al. Phytochemistry, Oxford, v.14, p.2213, 1975.

LIMA, L.C. Armazenamento de maçãs cv. Royal gala sob refrigeração e atmosfera controlada. Lavras: UFLA, 1999, 96p. (Dissertação de Mestrado)

MITCHAM, E. J.; MCDONALD, R.E. Cell wall modificaton during ripening of 'Keitt ' and Tommy Atkins" mango fruits. Journal of the American Society for Horticultural Science, Alexandria, VA, v.117, n.6, p.919-924, 1992.

MORETTI, C.L. Tecnologia de produtos minimamente procesados. In: CONGRESSO BRASILEIRO DE ENGENHARIAAGRÍCOLA, 30., 2001, Foz do Iguaçu-PR, 5 p.

PY,C.; LACOUEUILHE, J.J.; TEISSON,C. L'ananas: as culture sés produits. Paris:GP. Maisonneuve et Larose, 1984. 552p.

RANWALA, A . P.; SUEMATSU, C.; MASUDA, H. The role of $\beta$ galactosidases in the modification of cell wall components during muskmelon ripening. Plant Physiology, Washington, v.100, n.3, p.1318-1325, November 1992.

ROCHA, A.M.C.N.; BROCHADO, C.M.; MORAIS, A.M.M.B. Influence of chemical treatment on quality of cut aple (cv. Jonagored). Journal of Foood Quality, Trumbull, v. 21, p. 13-28, 1996.

VILAS BOAS, E. V. B. Maturação pós-colheita de híbridos de tomate heterozigotos no loco alcobaça. 1998. 105f. Tese (Doutorado) Universidade Federal de Lavras, Lavras. 1998. 